\title{
LA CARRERA JUDICIAL EN EL MODELO PERUANO
}

\author{
Ricardo Guillermo Vinatea Medina*
}

\section{Resumen:}

Partiendo de la hipótesis que en el Perú no existe la carrera judicial como tal, se emprende un estudio de la legislación nacional vigente, antecedentes y proyectos, para luego presentar una visión de cómo se desarrolla ésta en diversos países y concluir exponiendo algunas propuestas que deben tenerse en cuenta en una futura ley sobre el tema.

Palabras Clave: Carrera Judicial - Sistema cerrado, abierto o mixto.

\begin{abstract}
A bstract:
Starting from the hypothesis that in Peru does not exist the Judicial career itself, it is necessary to begin a study of the current national legislation, antecedents and projects, to display a vision of how it is developed in different countries. Finalizes with some proposals that should be consider un future laws on this affair.
\end{abstract}

Key words: Judicial career - Closed, opened and mixed systems.

\section{Sumario:}

1. La Carrera Judicial. 2. Carrera Judicial en Ia Legislación. 3. La Carrera Judicial en la Reforma de la Administración de Justicia. 4. Proyecto de Ley de Carrera Judicial. 5. La Realidad Nacional y la Carrera Judicial. 6. Conclusiones.

\footnotetext{
Vocal Provisional dela Primera Sala Penal Transitoria de la Corte Suprema de Justicia de la República.
} 


\section{HIPÓTESIS DE LA INVESTIGACIÓN}

Es conocido por todos que la sociedad actual exige magistrados con principios y valores, poseed ores de claros dotes de honestidad, idoneidad, debidamente capacitados y conocedores del entorno social, cultural, económico y político, sin embargo, también se requiere magistrados de experiencia, verdaderos expertos en actividad jurisdiccional, que conozcan la realidad del sistema de justicia y en especial la del sistema judicial, como complemento de su conocimiento de la realidad nacional; reunir estas virtudes y atributos resulta bastante difícil dentro de la normativa nacional vigente, en la cual la carrera judicial no existe.

En efecto, tanto la Constitución Política del Perú como la Ley Orgánica del Poder Judicial si bien es cierto asientan las bases para un Estatuto del juez, también lo es que carecen de orden sistemático en su concepción, una cosa es el reclutamiento o ingreso a la carrera judicial y otra muy distinta la promoción y ascenso de los magistrados, es en tal desorden dondeseconfunden ingreso, ascenso, conclusión de la carrera judicial, con el desarrollo de la misma y derechos de los jueces; no se ha concebido la existencia de una auténtica carrera judicial ni mucho menos se busca promoverla.

No es posible concebir un modelo como el nuestro sin la existencia de incentivos para desarrollar la carrera judicial, quien ya es juez no tiene la viabilidad legal para ascender en forma directa gracias a sus méritos y buen desempeño. No setrata de establecer premios, pero si de incentivar al buen magistrado para que continúe redoblando esfuerzos, se desempeñe con eficiencia y eficacia, procure capacitarse más y mejor con miras a optimizar el servicio de justicia, pero con el aliciente de queserá promovido al cargo jerárquico superior hasta llegar a la máxima jerarquía judicial.

Lo que tenemos en el escenario nacional es un modelo total mente abierto tanto para el ingreso (con estro concordamos). como para el ascenso, no obstante ser dos cosas total mente distintas, eso es prueba de que aún no se define el perfil de magistrado adecuad o a nuestra real idad nacional, a esto agregamos que recorrer los cargos jerárquicos deabajo hacia arriba fomentará magistrados con mejor formación jurisdiccional. No negamos quesecondice con el Estado constitucional y la democracia que se permita una apertura hacia abogados ajenos al Poder Judicial y a la actividad jurisdiccional, pero opinamos que no es adecuado en todos los niveles jerárquicos, sino que 
debelimitarseal ingreso ala carrera; no debemos olvidar quea la magistratura se debe ingresar por vocación, con el afán de prestar un servicio -en este caso de justicia- además de satisfacer las aspiraciones personales del postulante, consecuentemente, solo el profesional quetenga una verdadera inclinación por la judicatura se esmerará en su función y estará dispuesto a empezar la carrera desde abajo es decir desdeel grado jerárquico inferior.

Este problema se percibe claramente en las normas relativas al Consejo Nacional de la Magistratura, institución autónoma consagrada constitucionalmente y dotada de una ley orgánica, donde se le otorga competencia para sel eccionar, nombrar, ratificar y destituir a jueces y fiscal es detodos los niveles, salvo los provenientes deelección popular. A unquela normatividad no hace referencia al ascenso de jueces y fiscales, el señalar expresamente que selecciona a jueces y fiscales de tod os los niveles implica un sistema abierto para el ingreso y ascenso, situación que cuestionamos severamente pues, lejos de fortalecer debilita al Poder Judicial y al magistrado, en especial al permitir el ingreso deabogados queno conocen el desarrollo de la actividad jurisdiccional en los niveles jerárquicos inferiores; entonces, atendiendo a ello, cómo podrá resolver acertadamente sobre grados queno conoce.

Desde luego que estos problemas pertenecen a todo el sistema de justicia, por ello es preciso real izar una reforma constitucional más allá de elaborar una Ley de Carrera Judicial bastante defectuosa que tan solo persigue reglamentar al juez, rodeándolo de múltiples exigencias -lo que de por sí no es malo pues se debe rendir cuentas- pero no se debe soslayar que también se requiere modificar profundamente el sistema procesal; por ejemplo, tendiendo a la oral idad, dotándolo de tecnol ogía y reducirlo estrictamentea lo jurisdiccional, el marco quedeello resulte será propicio para los resultados, control y exigencias que se pretenden en la propuesta legislativa sobre la mal Ilamada carrera judicial.

\section{CAPÍTULO I}

\section{LA CARRERA JUDICIAL}

\subsection{C arrera judicial. C aracterísticas}

Primero debemos establecer en que consiste la carrera judicial, ya hemos referido que en el modelo peruano, no existe carrera judicial, además se 
confunde en un solo todo el ingreso y el ascenso. Guarneri ${ }^{1}$ expone acerca del reclutamiento como relevantepara el funcionamiento del sistema jurídico y para la calidad global de la justicia, refiere tres clases de mecanismos: designación por parte del ejecutivo o legislativo, elección ciudadana directa y concurso público, modalidades que dependen del sistema jurídico decada país sean del civil law o common law, el primero tiende al reclutamiento burocrático y el segundo al profesional. A nuestro parecer, el reclutamiento no solo significa el ingreso sino también el inicio de la carrera judicial, por otro lado, el ascenso es escalar posiciones de acuerdo al orden jerárquico e implica la consolidación de la carrera judicial. Por su parte, Gonzáles Mantilla² distingue claramente al sistema de ingreso, régimen de ascensos y terminación en el cargo, como presupuestos básicos dela carrera judicial, asimismo, con mucho acierto, concibe la diferencia entreambos, al definir al primero como un componente estructural que es punto de partida de la carrera judicial, al segundo como una sucesión ascendente de niveles ordenados jerárquicamentey al tercero como conclusión de la carrera. Para el presente trabajo el presupuesto que más interesa es el del ascenso, como desenlace y cristalización de la carrera judicial.

\subsection{Carrera judicial e independencia}

Sin lugar a dudas la carrera judicial es un componente esencial que contribuye a consolidar la independencia judicial. Guarneri ${ }^{3}$ citando a Di Federico señala que el reclutamiento de jueces es rel evante para la calidad global del servicio de justicia y el desempeño de los jueces depende de su competencia profesional y la forma en que son el egidos. A nuestro parecer, estas inferencias son correctas, por lo que una adecuada selección de magistrados contribuirá a la independencia e imparcial idad fortaleciéndola frente a cual quier influencia de las partes, de terceros o aún ante grupos de poder oficial o privado. Por ello, es necesario seleccionar a los profesionales con mayores cualidades y eliminar las interferencias políticas. Estos caracteres se reproducen en lo que respecta al ascenso como presupuesto o garantía de independencia del operador de justicia.

\subsection{Estatuto del juez}

El ordenamiento constitucional y legal vigente regula en forma inadecuada y genérica el estatuto del juez, además, lamentablemente omite consagrar la promoción de la carrera judicial, no obstante constituir presupuesto 
importante para el propio estatuto. Comparando el modelo peruano con otros modelos de carrera judicial Gonzáles Mantilla ${ }^{4}$ expresa que el ordenamiento peruano no contiene la carrera judicial, sino un conjunto de normas que rigen desordenadamente el estatuto del magistrado eimpiden identificar su rol en el sistema político.

Esto resulta contradictorio, pues el estatuto debecontener la carrera judicial, además de su desarrollo, los derechos del juez, responsabilidad disci plinaria, así como los principios y valores que consagran su desempeño, con arreglo a los principios y valores consagrados en la Constitución y las leyes.

\section{CAPÍTULO II}

\section{CARRERA JUDICIAL EN LA LEGISLACIÓN}

\subsection{La carrera judicial en la Constitución Política del Perú}

La carrera judicial se deriva tácitamente de los artícul os 138으, 143이 $150^{\circ}$ en cuanto establece la función jurisdiccional ejercida por el Poder Judicial a través de sus órganos jerárquicos jurisdiccionales (Corte Suprema, Cortes Superiores, Juzgados), y encarga la sel ección y nombramiento de jueces de todos los niveles al Consejo Nacional de la Magistratura.Sin embargo, no consagra expresamente la promoción de la carrera judicial como garantía de independencia e imparcialidad.

\subsection{La carrera judicial en la Ley O rgánica del Poder J udicial}

Regula en forma inadecuada e insuficiente la ll amada carrera judicial, sus artícul os 2240 y $225^{\circ}$ establecen un sistema de acceso y ascenso abierto, lo cual constituye una negación al ascenso directo; según Gonzáles M antilla ${ }^{5}$ no señala los principios que deben regirla, no la clasifica por fases, ni señala las características de cada grado ni fija los diversos regímenes de los magistrados, tampoco desarrolla cada uno de los presupuestos de la carrera judicial -ingreso, ascenso, terminación- por el contrario, incorpora aspectos ajenos a ella como los requisitos para ser magistrado, régimen laboral, disciplinario, estabilidad, etc.; crítica que de hecho compartimos por ser una prueba más de la ausencia de carrera judicial en el modelo peruano. 


\subsection{La carrera judicial en la Legislación Comparada}

En Inglaterra la selección de jueces es de carácter profesional, se efectúa entre los abogados más destacados (barrister). En los Estados U nidos el proceso de selección de los jueces federal es está a cargo del ejecutivo, la asociación de abogados (A merican Bar Association) y los partidos políticos; la elección es de orden profesional, directa y vitalicia, no existe uniformidad en la sel ección a nivel estatal. En España se sel ecciona a los jueces entre los abogados postulantes que cumplan los requisitos correspondientes y de acuerdo al orden de mérito, los el egidos deberán aprobar un curso de capacitación en la Escuela Judicial del Consejo General del Poder Judicial; la sel ección para plazas de magistrados (jueces superiores y supremos) se cubre por el sistema de cuotas (ascenso directo, concurso cerrado, abogados en ejercicio y secretarios judiciales). En Francia, igual que en España, la organización judicial está integrada por jueces de carrera, la sel ección se real iza entre los letrad os que aprueben el examen general para incorporarse a cursos especializados entre cuyos alumnos aprobados se nombrará a los jueces, se toma en cuenta antigüedad y aptitud.

Según Fix Fierro ${ }^{6}$, en México los jueces son servidores públicos y la carrera judicial es jerárquicamente estructurada, los letrados que ingresan reciben capacitación y entrenamiento específicos, el ascenso depende delos méritos y antigüedad requisitos que tornan en cerrada la carrera judicial en Ia justicia federal mexicana. Los vocal es supremos en Guatemala participan en el proceso de nominación las al tas cortes y universidades que formulan ternas para que elija el Congreso. En cuanto al órgano seleccionador en Argentina, el Consejo de la Judicatura previo concurso público presenta ternas al Ejecutivo; en Bolivia el Consejo de la Judicatura proponelistas al Congreso para el nombramiento de jueces de apelaciones y primera instancia; similar es en Paraguay donde el Consejo de la Judicatura proporciona ternas al Senado para candidatos a la Corte Suprema y Tribunales Superiores nombran los jueces inferiores. En Costa Rica, Ecuador, El Salvador, México, el Consejo de la Judicatura selecciona y nombra a los jueces. Finalmente, $\mathrm{Nicaragua}$ cuenta con una Comisión de Carrera Judicial conformada por la Corte Suprema, el eva a Ia Sal a Plena las ternas de candidatos para las plazas vacantes de magistrados de tribunales de apelaciones y jueces. 
En Colombia, al igual queen Perú, seingresa a la carrerajudicial en cualquier nivel jerárquico mediante proceso abierto. Por su parte, en Chilee Italia de juez a magistrado superior el ascenso es directo mediante proceso cerrado y nuevamenteabierto para magistrado del Tribunal Supremo.

\section{CAPÍTULO III}

\section{LA CARRERA JUDICIAL EN LA REFORMA DE LA ADMINISTRACIÓN DEJUSTICIA}

\subsection{Comisión de M agistrados para la Reestructuración Judicial}

Instaurada por Resolución Administrativa № 035-2003-P-PJ publicada en el diario oficial "El Peruano" el 14 de febrero de 2003, fue una reacción al interior del Poder Judicial, planteó la necesidad de contar con una ley de carrera judicial, desafortunadamente sus iniciativas y propuestas tuvieron escaso efecto.

\subsection{A cuerdo $\mathrm{N}$ acional por la J usticia}

Este programa fue cread o por Resolución A dministrativa de la Presidencia del Poder Judicial № 191-2003-P-PJ de 22 de octubre de 2003, también fue iniciativa del Poder Judicial, planteó el aborar el Pacto Social por la Justicia con objetivos a mediano y largo plazo, así como lineamientos general es de la política judicial para veinte años, conformó un grupo impulsor para la conducción del acuerdo. Mediante Resolución Administrativa de la Presidencia del Poder Judicial № 205-2003-P-PJ de 19 de noviembre de 2003 fueron señaladas las actividades a cumplir con el objeto de elaborar propuestas de políticas para el Poder Judicial y presentarlas al CERIAJUS.

El informe final, en forma consensuada con la sociedad civil, propuso políticas de Estado para el cambio estructural del Poder Judicial, en cuanto a la política de fortalecimiento de la autonomía eindependencia se decidió promover la estabilidad de los magistrados y otros mecanismos que garanticen su independencia e imparcialidad, así como la titularidad plena de los magistrados, en los lineami entos operativos respectivos incluyó la aprobación de una nueva Ley Orgánica del Poder Judicial y deun Estatuto Nacional del Juez conforme a estándares internacionales, así como la formulación desistemas de evaluación del juez. Respecto a la política de 
personal y recursos humanos, propuso impulsar la incorporación al Poder Judicial de magistrados idóneos y honestos con sólida formación académica y profesional eimbuidos de valores y ética, para ello plantearon promover un perfil del magistrado acorde con las necesidades institucional es, la selección y nombramiento de magistrados honestos e idóneos de acuerdo al mérito personal y profesional, para cuyo efecto estableció entre otros lineamientos operativos la promul gación de una ley de carrera judicial.

En consecuencia, se aprecia que lograron consensos para impulsar y garantizar la carrera judicial.

\subsection{Comisión Especial para la Reforma Integral de la A dministración de Justicia}

Creada por Ley №28083, publicada el 04 de octubre de 2003, el 24 deabril de 2004 entregó al Ejecutivo el Plan Nacional para la Reforma Integral del Si stema de Justicia el aborado en forma concertada con representantes de la sociedad civil, en cuanto a las áreas temáticas incluyó la carrera judicial, selección, nombramiento y formación de jueces, gran partes de las propuestas dela CERIAJUS no se han Ilevado a efecto por falta de decisión política.

\section{CAPÍTULO IV}

\section{PROYECTO DE LEY DE CARRERA JUDICIAL}

\subsection{A spectos principales}

Se han presentado diversas iniciativas como el Proyecto de Ley № 176/ 2006-CR del congresista Raúl Castro Stagnaro su fecha 31 deagosto de 2006 que sustituye las Secciones Cuarta y Quinta del TUO dela Ley Orgánica del Poder Judicial referentes al régimen delos magistrados y a la carrera judicial.

Con fecha 21 de junio de 2007 la Comisión de Justicia y Derechos Humanos expidió dictamen respecto a las observaciones del Poder Ejecutivo a la autógrafa de la Ley de Carrera Judicial (Proyectos No 176/ 2006-CR, 229/ 2006-PE, 268/ 20066-CR, 304/ 2006-PE, 469/ 2006-CR, 1169/2006-CR ingresados a la Comisión el 27 de abril de 2007). 
Por último, el 08 denoviembre de 2007 seexpidió el Texto Sustitutorio dela Ley de Carrera Judicial (Proyectos № 176/ 2006-CR, 229/ 2006-PE, 268/ 20066-CR, 287/ 2006, 304/ 2006-PE, 469/ 2006-CR, 549/ 2006).

Como aspectos principales del Proyecto de Ley deCarrera Judicial debemos destacar la existencia de principios rectores de la misma tales, como la independencia e imparcialidad, ética y honestidad; el reconocimiento de los méritos logrados por el juez como presupuesto para permanencia y promoción en la carrera; el debido proceso en los procesos disciplinarios, Se plantean, en el Proyecto, objetivos claros para la carrera; se esboza un perfil ideal del juez; se establecen las fases y etapas del proceso de ingreso a la carrera judicial, se establecen parámetros para la evaluación curricular, evaluación psicológica y entrevista personal y su peso calificatorio; muy importantees el establecimiento de la formación y capacitación permanente; asienta el derecho a la evaluación de desempeño y a la especialidad; formula un régimen disci plinario graduado y exigente; incorpora los jueces supernumerarios y candidatos en reserva; desarrolla la evaluación de desempeño y le otorga dicho rol al Consejo N acional de la Magistratura, crea la Comisión de Evaluación del Desempeño como órgano ejecutivo, a la cual autoriza a recurrir a órganos de apoyo, auxiliares y colaboradores. Por vez primera se contempla el otorgami ento de beneficios e incentivos por buen desempeño de los jueces de carrera, contempla cuota del 30\% para los ascensos directos de los jueces al grado jerárquico inmediato superior.

\subsection{M odalidad de selección y ascenso adoptado en el Texto Sustitutorio del Proyecto Ley de Carrera Judicial}

En primer lugar, admite que los abogados puedan postular a todos los nivel es de la carrera judicial, esto se desprende de los requisitos especiales para el ingreso a la carrera judicial fijados en el Capítulo II del Título II; en segundo lugar, por el hecho de establecer cuotas para el ascenso directo de los jueces, interpretamos que el texto sustitutorio adopta un sistema mixto de selección y ascenso respecto a jueces de paz letrados y jueces especializados o mixtos, vale decir, para la postulación de jueces de paz letrados a juez especializado o mixto y de estos últimos a juez superior; tercero, para la selección y ascenso de juez superior a juez supremo el sistema estotalmente abierto. 


\subsection{C ríticas a la propuesta legislativa}

N uestra crítica la centramos desde el punto de vista de la hipótesis inicial formulada en el plan detrabajo, así consideramos que el modelo deingreso y ascenso a la judicatura ad optado por la ley comentada no es consecuente con una carrera judicial apropiada para las necesidades y objetivos de la reforma judicial; en tal sentido, si en los principios rectores se estima el mérito como presupuesto para el ingreso, permanencia y promoción en la carrera judicial, igualmente, en las disposiciones generales seestablece que la carrera judicial regula el ingreso, permanencia, ascenso y terminación en el cargo de juez, resulta incongruente que se ad opte un model o que debilita la carrera judicial.

En efecto, el tratamiento legal conferido a los objetivos dela carrera judicial no es consecuente con lo desarrollado para cada presupuesto, no se regula como un todo el ingreso y el ascenso, por el contrario, se les trata como aspectos distintos; asimismo, el ingreso merece mayor desarrollo en la ley y el ascenso apenas es enunciativo y casi aislado (artículo 99o del texto sustitutorio).

Tampoco es acorde el referido tratamiento con el sistema de concurso adoptado. Así, no es posible promover la carrera judicial si permite tímidamente (solo por cuotas) el ascenso directo hasta juez superior. Por qué no adoptar el sistema de promoción por mérito a través de concurso reservado a jueces y magistrados (jueces superiores) de grados inferiores a la vacante, como es el caso de Chile; o, en todo caso, si se invoca mayor apertura u oxigenación del Poder Judicial, por quéno se toma el sistema de promoción por turnos utilizado en España con parte de las vacantes para juristas de reconocida competencia y con un mínimo de años en el ejercicio profesional. Sobreel particular opinamos que estos dos sistemas -el uno en mayor grado que el otro- propugnan una auténtica carrera judicial y fortalecen el estatuto del juez en general.

Un sistema abierto es definitivamente incoherente con la carrera judicial debido a que por un lado minimiza tan importante presupuesto como es la vocación para ser juez y por otro permite que profesionales ajenos a la organización judicial puedan postular directamente a los grados de mayor jerarquía el udiendo los grados jurisdiccionales inferiores, lo que obviamente constituye una discriminación y atenta contra el derecho de igual dad ante 
la ley de los jueces que están sujetos a su grado jerárquico y solo pueden escalar al inmediato superior.

\section{CAPÍTULO V}

\section{LA REALIDAD NACIONAL Y LA CARRERA JUDICIAL}

\subsection{La realidad de la carrera judicial en el Perú}

A la luz de lo expuesto, considerando el sistema legal vigentey la propuesta legislativa en cuestión, sin lugar a dudas reiteramos que no existe carrera judicial en el modelo peruano.

Si analizamos quese pretende con la reforma judicial, podemos afirmar que entre los fines generales están mejorar la admi nistración dejusticia, contando para ello con magistrados de inquebrantable vocación, premunidos de principios y valores, debidamente capacitados y con sólida experiencia, por consiguiente, se debe formar jueces con tales calidades, lo que imprescindiblementerequiere un prolongado proceso primero deinducción y después de capacitación permanente, para así esperar que los mejores vayan escalando posiciones, de modo tal queal llegar a la máxima instancia se encuentren preparados para contribuir a la consolidación del estado constitucional y democrático, salvaguardar los derechos fundamentales, la estabilidad jurídica y orientar las políticas jurisdiccionales.

En consecuencia, el sistema de carrera judicial adoptado jamás al canzará tal es metas, por tal motivo la reforma debe recorrer otro camino más acorde con la realidad nacional.

\subsection{M odalidad de selección y ascenso adecuada a nuestra realidad nacional: procesos abierto, cerrado o mixto}

En posición acorde con lo expuesto en los capítulos precedentes, tenemos que desembocar en la el ección entre el sistema cerrad o o mixto. El primero más definido y consecuente con la carrera judicial, aunque satanizado por voceros o juristas ajenos al Poder Judicial con una visión parcial del problema (solo desde afuera), sistema que únicamente concede acceso abierto por el nivel jerárquico inferior, para luego impulsar el ascenso de los jueces gradualmente de acuerdo a los méritos logrados y buen desempeño. El 
segundo sistema, con cierta flexibilidad, establece por un lado el sistema cerrado exclusivo para jueces y por otro, cuotas de acceso abierto en todos los niveles para abogados calificados -aunque considero que estas cuotas deben ser en menor porcentaje en aras dela apertura democrática eigualdad de oportunidades, este es un sistema bastante aceptable. Sin embargo, particularmente nos inclinamos por el sistema cerrado.

\subsection{Carrera judicial como expectativa individual y social}

No debemos olvidar que en la carrera judicial, como en todo orden de cosas, al lado de las expectativas de la sociedad se encuentran implícitas las expectativas individuales identificadas como la vocación a la judicatura, la necesidad de incentivos para colmar tal es pretensiones personales a efectos de tener un desempeño premunido de condiciones de trabajo adecuadas a las exigencias laborales y a la mayor o menor dificultad del cargo, de modo quese esté en condiciones de responder con acierto y oportunidad.

Tales conceptos difícilmente se reflejan en la normatividad vigente o propuesta de la carrera judicial, el juez es un ser humano que espera satisfacciones por el esfuerzo desplegado, por consiguiente el sistema adoptado debe otorgársel as como garantía del éxito al canzado.

\subsection{N uestra propuesta}

Proponemos se realicen las reformas constitucionales y legal es pertinentes a fin de lograr un escenario apropiado en el cual sea posible plasmar la propuesta siguiente:

El Consejo Nacional de la Magistratura debe encargarse de la selección y nombramiento de los jueces de paz letrados y de promover la carrera judicial, a efectos de que quien tiene inclinación por la judicatura se inicie a partir del grado jerárquico inferior, esto causará que postulen los abogados que tengan una verdadera vocación para ser juez y estén dispuestos a recorrer gradual mente todos los niveles de jerarquía.

Con arreglo a su nuevo rol, el Consejo Nacional de la Magistratura será el encargado de, en virtud a los informes que recabe por parte dela Comisión de Evaluación del Desempeño respecto a los méritos, mejor capacitación y buen desempeño de los jueces, decidir quienes son los que deben ascender 
directamenteal grado inmediatamentesuperior; o en caso necesario, previo concurso, si existepluralidad decandidatos seleccionados con aspiraciones a la misma vacante.

\section{CONCLUSIONES}

1. Según la forma como está estructurada la normatividad constitucional y legal en el Perú, no se propicia la carrera judicial debido a la incongruencia del tratamiento de los presupuestos en su diseño.

2. El ingreso a la carrera judicial debe ser por concurso abierto en su base, es decir, se debe iniciar desde grado jerárquico inferior.

3. A fin de fortalecer la administración de justicia, la independencia e imparcialidad delos jueces y su estatuto es necesario optar por el sistema de promoción por mérito a través de concurso cerrado.

4. Los ascensos deberán ser del grado inferior al inmediato superior a fin de conseguir jueces con vasta experiencia y capacidad.

5. Constituye presupuesto importante para la evaluación correspondiente la vocación por el servicio de justicia que posea el postulante.

6. Así diseñada, la carrera judicial constituirá un incentivo para el juez para continuar con la misma hasta su conclusión, en el entendido de que sus esfuerzos, calidades y correcto desempeño serán reconocidos mediante el ascenso directo.

\footnotetext{
1 Guarneri, C. El acceso a la función judicial. Estudio comparado. Material de Estudio, Organización de la Jurisdicción, págs. 1 a 13.

2 Gonzáles Mantilla, G. Pensamiento constitucional. La organización dela jurisdicción en el Perú. Material de estudio, Organización de la Jurisdicción, págs. 4 a 6.

3 Guarneri, C. Op cit, pág. 5.

Gonzáles Mantilla, G. Op cit, pág. 23.

Gonzáles Mantilla, G. Op cit, pág. 35.

6 Fix Fierro, H. "Los consejos de la judicatura entre profesión y organización", Coloquio internacional sobre el Consejo de la Judicatura, México, 1995. En Jurisdicción Federal y Carrera Judicial en México, Cossío Díaz, José Ramón.
} 